\title{
Recomeçar com Marx
}

Ivo Tonet ${ }^{1}$

Nosso objetivo, nessa comunicação, é discutir a questão da reconstrução da teoria marxiana, buscando mostrar porque o caminho da ontologia do ser social é mais produtivo para essa empreitada.

Para a maioria dos intelectuais, Marx não passa, hoje, de um "cachorro morto". Não por acaso, esses intelectuais também abriram mão, se alguma vez acreditaram nisto, de qualquer perspectiva revolucionária em relação à atual ordem social.

Contudo, para aqueles que entendem que o capitalismo agrava cada vez mais os problemas da humanidade e, portanto, deve ser superado, a reconstrução da teoria revolucionária é uma das tarefas mais importantes neste momento. E, no seu interior, o resgate do pensamento marxiano ocupa um lugar centralíssimo. Ambas as tarefas têm uma enorme urgência e importância, dado o extravio e a confusão em que se vê enredada a luta anti-capitalista na atualidade. Pretendemos, aqui, restringir-nos apenas à problemática do marxismo.

A primeira questão, pois, que se coloca é: qual o sentido deste resgate? Para alguns trata-se, apenas, de defendê-lo dos ataques dos seus adversários e de corrigir eventuais deformações historicamente situadas. Para outros, levando em consideração as enormes mudanças que o mundo sofreu desde o nascimento do marxismo até hoje, trata-se de buscar estabelecer "o que é vivo e o que é morto" nele, atualizando-o face

$--\cdots$

1 Professor do Departamento de Filosofia da Universidade Estadual de Alagoas.

cadernos cemarx, $\eta^{0} 2-2005 \mid 89$ 
aos problemas do mundo atual. Para isto, há quem advogue a necessidade de entrecruzá-lo com outras correntes atuais, o que permitiria evitar todo dogmatismo e sectarismo e traria mais produtividade ao próprio marxismo.

Não nos parece que estes sejam os melhores caminhos para essa reconstrução. Ao nosso ver, quase nenhuma das interpretações conseguiu captar ou restituir ao ideário marxiano aquele caráter radicalmente crítico e revolucionário que é sua característica mais essencial. Independente do quantum realizado e dos erros e acertos, acreditamos que a vertente chamada de ontologia do ser social, cujo expoente maior é G. Lukács ${ }^{2}$, é a que melhor contribuiu para isso.

Nesta perspectiva, não se trata só de correções nem apenas de atualizações. Considerando as variadas interpretações, extravios e deformações que este pensamento sofreu ao logo da sua trajetória, como resultado de todo um processo histórico, impõe-se a necessidade de recomeçar ab initio. Sabe-se que o pensamento marxiano se configurou com uma clara perspectiva revolucionária, ou seja, de superação radical da ordem burguesa. E foi precisamente este caráter radical e revolucionário que ele foi perdendo ao longo da sua trajetória. E entre as inúmeras deformações que ele sofreu está a redução desta radicalidade ao campo da política, quando a questão é muito mais ampla e profunda. Ser radical, como o próprio Marx diz, é ir à raiz. Ora, continua ele, a raiz do homem é o próprio homem. Trata-se, pois, ao nosso ver, de retornar a Marx ${ }^{3}$, não para encontrar o "verdadeiro Marx" - tarefa impossível e sem sentido mas, para buscar nele os fundamentos (a raiz) de uma compreensão radicalmente - e porque radical, revolucionária - do mundo dos homens.

Defendemos a idéia _ aparentemente absurda diante da situação em que se encontra o marxismo hoje - de que Marx realizou uma revolução teórica similar, mutatis mutandis, àquela realizada pelos pensadores modernos dos séculos XVII e XVIII; de que Marx lançou os fundamentos de uma concepção radicalmente nova de mundo e de que por isso ele representa o patamar de conhecimento mais elevado que a humanidade produziu até hoje. Fundamentos estes que não têm sua validade limitada a

$-\cdots-\cdots$

2 Gyorgy Lukács, Ontologia dell'Essere Sociale. Roma, Riuniti, 1976-1981. Ver, também, do mesmo autor: Prolegomeni all'Ontologia dell'Essere Sociale. Milano, Guerini e Associati, 1990.

3 Para o pensamento desse autor, ver dele: A questão judaica. São Paulo, Moraes, 1991; 0 capital. Rio de Janeiro, Civilização Brasileira, 1975; Elementos fundamentales para la critica de la economia política. México, Siglo XXI, 1978 e de K. Marx e F. Engels, A ideología alemã. São Paulo, Hucitec, 1986.

90 Recomeçar com Marx 
determinado campo específico, mas que permitem abordar qualquer fenômeno social com possibilidades superiores a quaisquer outros instrumentais teóricos.

Para que não pairem dúvidas sobre o sentido de uma afirmação tão contundente e ousada - especialmente em um momento em que tudo parece demonstrar o contrário - esclarecemos que ela se refere apenas aos fundamentos e de modo nenhum ao que Marx realizou a partir deles. Quanto ele mesmo realizou em termos de conhecimento da realidade social, quais os seus acertos e erros, o que tem ou não validade para o mundo de hoje, são questões importantes, mas de outro tipo. Também queremos deixar claro que não se trata de diminuir ou menosprezar as contribuições muitas vezes geniais - de outros autores. O próprio Marx tinha consciência de que ele só pode fazer o que fez porque subiu nos ombros de outros gigantes. O sentido preciso da nossa afirmação é este: Marx lançou os fundamentos de uma concepção radicalmente nova e superior de fazer ciência e filosofia e, portanto de compreender o mundo. E - ponto decisivo - desta própria compreensão decorre a possibilidade e a necessidade de uma transformação radical do mundo. Vale dizer: o fundamento da luta revolucionária está, primeiramente, na ontologia e só depois na ética e na política.

Como, então, fazer emergir este caráter radicalmente crítico e revolucionário do pensamento marxiano? O que é que lhe confere este caráter radicalmente crítico e revolucionário?

Entendemos que a resposta a essas questões só pode ser obtida se observarmos três princípios metodológicos fundamentais: buscar a gênese histórico-ontológica; compreender a função social e fazer uma análise imanente. Cremos que a observação destes três princípios nos permitirá apreender o pensamento marxiano como o patamar de conhecimento mais elevado que a humanidade atingiu até hoje e, por conseqüência, o melhor instrumento teórico para orientar a transformação do mundo.

Parece não haver dúvida de que, na passagem do feudalismo ao capitalismo, houve uma revolução teórica. E que os pensadores burgueses, expressando uma nova e emergente forma de sociabilidade, liderada pela burguesia, realizaram a crítica do modo greco-medieval de pensar (centrado no ser, metafisicamente entendido) e lançaram as bases de uma nova forma de fazer ciência e filosofia (centrado no conhecer, abstratamente concebido). Afinal, toda classe que pretende alcançar o poder é obrigada a fazer a crítica do modo de pensar das classes que combate e estabelecer fundamentos para um conhecimento e uma ação adequados aos seus objetivos.

Ora, assim como a burguesia é o sujeito fundamental da sociabilidade do capital, a classe trabalhadora tem o mesmo estatuto em relação a uma forma de sociabilidade

cadernos cemarx, $n^{0} 2-2005 \mid \mathbf{9 1}$ 
para além do capital. Deste modo, também a classe trabalhadora, por sua natureza (historicamente configurada), põe as bases para o surgimento de uma compreensão do mundo mais ampla, mais profunda e mais radical. É a própria natureza da classe trabalhadora que exige a transformação radical do mundo, a superação, pela raiz, da forma da sociabilidade regida pelo capital. Mas, para que essa transformação não fosse apenas um desejo, uma utopia, seria preciso uma fundamentação sólida, uma demonstração rigorosa da radical historicidade e socialidade do mundo dos homens. Vale dizer, seria preciso elevar ao nível da consciência, dar forma teórica àquelas possibilidades existentes na realidade social burguesa; demonstrar que a realidade social é obra exclusiva - ainda que não absoluta - dos próprios homens. E, para isso, seria preciso alterar radicalmente o ponto de partida. Como o próprio Marx diz: em vez de partir do céu para a terra, ou seja, de dogmas ou especulações arbitrárias, frutos da consciência, seria preciso partir da terra para o céu, vale dizer, do real, do efetivamente existente, do empiricamente verificável.

Como Marx faz isso? Tomando como ponto de partida a realidade (social) efetivamente existente, Marx resgata a centralidade da objetividade (característica da perspectiva greco-medieval), - daí o caráter ontológico do seu pensamento - subordinando a esta a resolução de todas as questões relativas ao conhecimento. Demonstra, porém, que esta objetividade é radicalmente histórica e social. Nesta empreitada, duas categorias são fundamentais: as categorias da essência/fenômeno e da práxis. Por um lado, ao historicizar a primeira e ao demonstrar a sua relação com o fenômeno, ele resolve os problemas da relação entre unidade e diversidade e entre permanência mudança no ser social. Por outro lado, ao demonstrar como a realidade social é sempre o resultado da determinação recíproca entre subjetividade e objetividade (teleologia e causalidade), porém sob a regência da segunda, e como a práxis é a categoria mediadora entre estes dois momentos, ele pode integrar harmonicamente aquelas duas categorias, superando, ao mesmo tempo, o idealismo e o materialismo mecanicista.

Com isso, ele supera tanto a unilateralidade da perspectiva greco-medieval (centrada no ser, mas metafisicamente concebido), como a unilateralidade da perspectiva moderna (centrada no conhecer, mas abstratamente entendido).

É no trabalho, portanto, como ele mesmo diz, um princípio empiricamente verificável, ("os indivíduos reais, sua ação e suas condições materiais de vida...") ${ }^{4}$, que ele

4 Karl Marx e Friedrich Engels. A ideologia alemã, op. cit., pp. ટ६-ટ7.

92 Recomeçar com Marx 
encontra a raiz, o fundamento ontológico-primário do ser social. A análise deste ato fundante permite-lhe demonstra a radical historicidade e socialidade do mundo dos homens bem como a natureza específica deste mundo. É também a análise do trabalho que lhe permite mostrar como surgem, com natureza e funções específicas, todas as outras dimensões sociais, garantido, deste modo, tanto o matrizamento ontológico quanto a autonomia relativa. Como resultado, o ser social emerge como uma totalidade articulada em processo, sem jamais perder essa característica, não importa quanta fragmentação possa resultar do andamento concreto da história.

Com isto, velhos problemas, como a questão da origem ontológica do homem e da natureza própria do mundo social; da relação entre espírito e matéria, consciência e realidade objetiva, ação e estrutura, unidade e diversidade, mudança e permanência, liberdade e necessidade, indivíduo e sociedade, sujeito e objeto, teoria e prática, ciência a ideologia, etc. têm sua resolução encaminhada sob uma ótica profundamente diferente e mais apropriada.

Do mesmo modo, com esta impostação podem ser facilmente refutadas quaisquer acusações de determinismo, economicismo, dogmatismo, menosprezo do indivíduo, metafísica, messianismo e tantas outras que resultam de leituras não ontológicas do pensamento deste pensamento.

Vale frisar: com isto não estão resolvidos todos os problemas. Estão apenas (e isto é muitíssimo importante) lançados os fundamentos, está aberto um patamar para a abordagem de qualquer fenômeno social e para impulsionar a compreensão, o mais profunda hoje possivel, da realidade social. Parece evidente que não vai nisto nenhum dogmatismo, pois estes fundamentos - eles mesmos sempre necessitados de crítica e aprofundamento - não garantem a correção e a superioridade do conhecimento produzido a partir deles, apenas a tornam possível.

Infelizmente, nem a versão dominante do marxismo - o marxismo da II Internacional e o chamado marxismo-leninismo - nem a maioria das outras interpretações compreenderam essa revolução filosófico-científica radical operada por Marx. As conseqüências negativas desta incompreensão foram enormes para a luta contra o capital. Impossível, sequer, mencioná-las, aqui. Mas, em síntese, tornaram o marxismo incapaz de enfrentar a ideologia burguesa e contribuíram poderosamente para extraviar a consciência dos que pretendem lutar contra o capital. Daí a necessidade premente de recomeçar com Marx, a partir dos fundamentos, na perspectiva ontológica indicada por Lukács, para resgatar o caráter radicalmente crítico e revolucionário do seu pensamento e, com isto, impulsionar a reconstrução da teoria revolucionária.

cadernos cemarx, $n^{0}-2-2005 \quad 93$ 